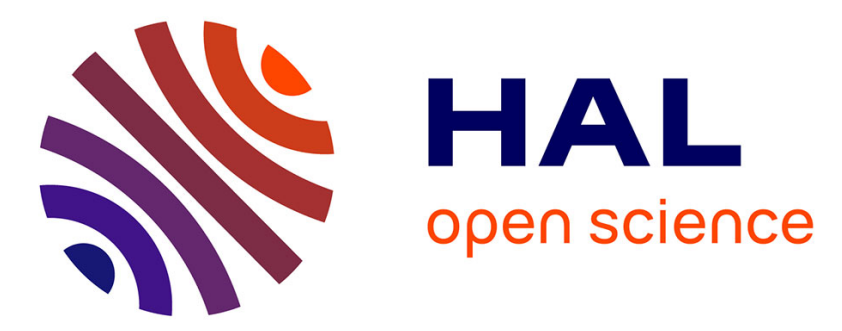

\title{
Comparing the analytical potential of PAS, PDS, TL and PTPS for trace detection of pesticides in water
}

\author{
W. Faubel, T. Schulz, B. Seidel, E. Steinle, H. Ache
}

\section{To cite this version:}

W. Faubel, T. Schulz, B. Seidel, E. Steinle, H. Ache. Comparing the analytical potential of PAS, PDS, TL and PTPS for trace detection of pesticides in water. Journal de Physique IV Proceedings, 1994, 04 (C7), pp.C7-531-C7-534. 10.1051/jp4:19947125 . jpa-00253179

\section{HAL Id: jpa-00253179 https://hal.science/jpa-00253179}

Submitted on 1 Jan 1994

HAL is a multi-disciplinary open access archive for the deposit and dissemination of scientific research documents, whether they are published or not. The documents may come from teaching and research institutions in France or abroad, or from public or private research centers.
L'archive ouverte pluridisciplinaire HAL, est destinée au dépôt et à la diffusion de documents scientifiques de niveau recherche, publiés ou non, émanant des établissements d'enseignement et de recherche français ou étrangers, des laboratoires publics ou privés. 


\title{
Comparing the analytical potential of PAS, PDS, TL and PTPS for trace detection of pesticides in water
}

\author{
W. Faubel, T. Schulz, B.S. Seidel, E. Steinle and H.J. Ache \\ Kernforschungszentrum Karlsruhe GmbH, Institut für Radiochemie, Postfach 3640, 76021 Karlsruhe, \\ Germany
}

\begin{abstract}
Performances of four related techniques i.e., photoacoustic spectroscopy, photothermal deflection, thermal lensing, and photothermal phase shift spectroscopy have been compared to the conventional beam transmittance spectrophotometry. This concerns to the analytical potential in studies of environmental pollutants. Solutions of pesticides in water are used as specimens in this study. Spectrophotometric, photoacoustic and thermal lensing techniques are also used as detector behind HPLC loaded with a mixture of methanol and water. Thermal lensing and photothermal deflection spectroscopy appear superior in determination of environmental pollutants. The detection limit obtained for pesticides is $0.1 \mu \mathrm{g} / \mathrm{kg}$.
\end{abstract}

\section{INTRODUCTION}

Techniques, such as photoacoustic spectroscopy (PAS), thermal lensing (TL), photothermal deflection spectroscopy (PDS), and photothermal phase shift spectroscopy (PTPS) are well recognized for their ability to measure low levels of absorption in transparent and opaque samples. Unlike conventional spectrophotometry, these methods measure the absorbed radiation directly. Advantages and disadvantages of the different techniques, mentioned above, have been discussed [1] and the results performed under various experimental conditions compared. In this paper we present for the first time results on the performance of PAS, PDS, TL, PTPS, and conventional spectrophotometry obtained under comparable experimental conditions.

\section{EXPERIMENTAL SET-UP}

The laser PA system used here is a single beam instrument reported elsewhere [2]. A pulsed dye laser pumped by a $\mathrm{XeCl}$ excimer laser is used as the excitation source. The dye laser beam ( $364 \mathrm{~nm})$ impinges a sample solution confined in a thermostated cell of stainless steel with quartz windows. A piezoelectric transducer (PZT) in acoustic contact with the sample is used to measure the amplitude of the resulting photoacoustic wave. The output signal of the piezoelectric transducer is fed, following low and high pass filtering, into a preamplifier, connected to a boxcar integrator.

The three experiments (PDS, TL and PTPS) have been performed in a transverse and a collinear arrangement using the following experimental set-up: A continuous wave UV argon ion laser (364 nm) beam, modulated between 2 and $10 \mathrm{~Hz}$ by a mechanical chopper, impinges into a quartz fluorescence cuvette. The radiation of HeNe probe laser $(632.8 \mathrm{~nm})$ has been focused to intersect at different angles $\left(0^{\circ}\right.$ or $90^{\circ}$ ) the excitation beam with or without offset appropriate to each individual photothermal method used. 


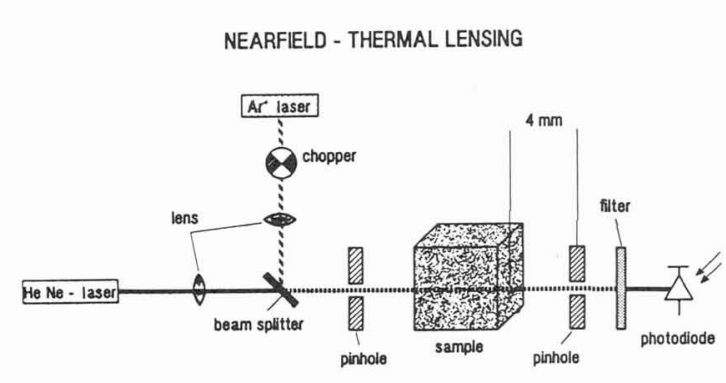

Fig. I: Scheme of Near Field Photothermal Lensing

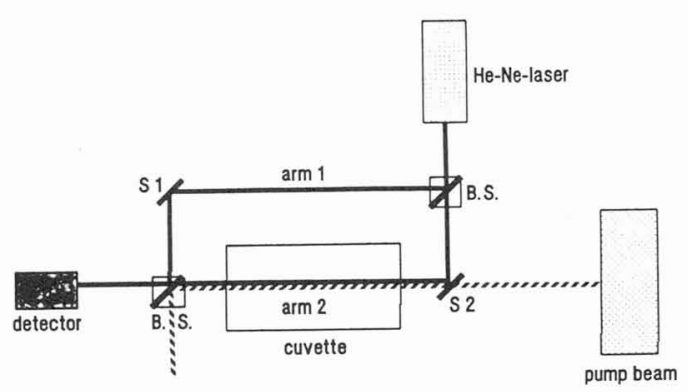

Fig. 2: Scheme of Photothermal Phase Shift Spectroscopy

In PDS scheme, the deflection of the monitoring beam is measured by a two-dimensional positionsensitive device. The pre-amplified $x$ - and $y$ - deflection signals are processed by two lock-in amplifiers as described earlier [3]. In thermal lensing, the position sensitive device used in PDS experiments for the monitoring of the HeNe probe beam is replaced by a photodiode. The distances between the pinhole and sample cell have been varied between $400 \mathrm{~mm}$ and $4 \mathrm{~mm}$, according to a far field and a near field thermal lensing (Fig. 1) geometry.

The photothermal phase shift (PTPS) measurements have been performed using a self-built Mach Zehnder interferometer (Fig.2), with the sample cell placed in one arm of the interferometer. The concentration of the analyte is determined on a Cary 2400 spectrophotometer. The samples have been prepared by dissolving pesticides such as 2-methyl-4,6-dinitrophenol (DNOC), 2-sec-butyl-4,6dinitrophenol (dinoseb), 2-tert-butyl-4,6-dinotrophenol (dinoterb) and 2,4 dinitrophenol (DNP) in distilled water. Furthermore, separations of various pesticides in aqueous solutions have been performed by using a high performance liquid chromatography in combination with a conventional ultraviolet -visible diode array (HPLC/UV), the photoacoustic (HPLC/PAS) and the thermal lensing (HPLC/TL), shown in Fig 3. For flow rates higher than $500 \mu \mathrm{l} / \mathrm{min}$, an HPLC pump at $1 \%$ flow rate accuracy (BT 3030, Biotronic) was used. A $5 \mu \mathrm{m}$ Lichrocart $100 \mathrm{RP}-18$ column (4 mm i.d., $250 \mathrm{~mm}$ long, Merck) and an injection valve (Negretti + Zambra, model 220) with a loop of $100 \mu \mathrm{l}$ were used. The cell volume was $8 \mu \mathrm{l}$ and pathlength $10 \mathrm{~mm}$. HPLC-grade methanol (mixed with distilled water, 75:25, v,v) has been the eluting solvent without further purification. The solvent has been degassed before use by a sonicator operated under vacuum for at least 1 hour.

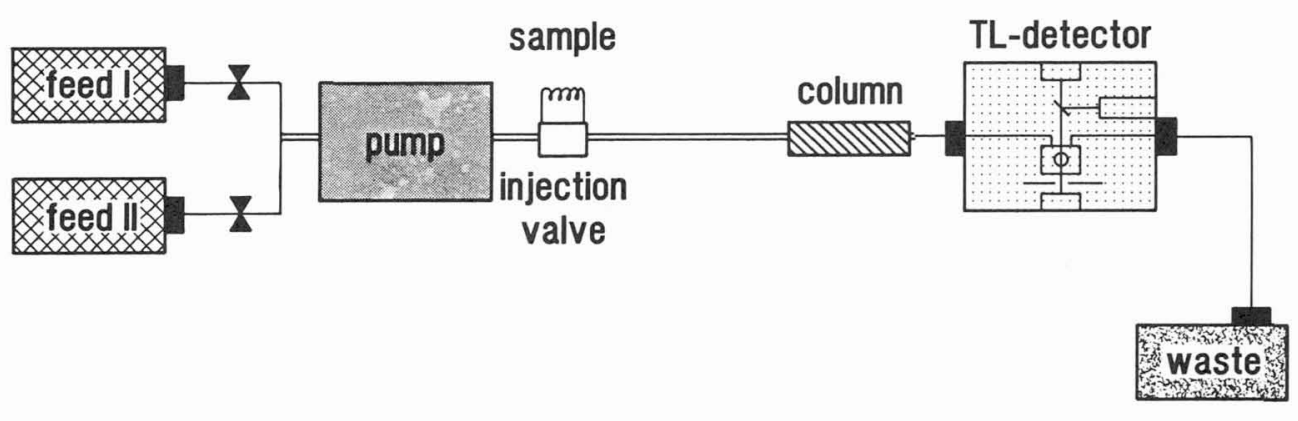

Fig.3: Schematic diagram of HPLC/TL detection system 


\section{RESULTS AND DISCUSSION}

\subsection{DNOC reference solution}

The measured detection limits for DNOC pesticide, as untreated standard solution, obtained with conventional Cary 2400 spectrophotometer on the one hand, and the photoacoustic and collinear photothermal techniques, on the other hand, are shown in table 1 :

Table 1: Comparison of detection limits for DNOC when using different techniques.

\begin{tabular}{|c||c|c|c|c|c|}
\hline DNOC & Limits & of & detection & \\
\hline in & Cary 2400 & PAS & PDS & TL & PTPS \\
\hline \hline $\mathrm{g} / \mathrm{kg}$ & 15 & 8 & 0.3 & 0.1 & 3 \\
\hline
\end{tabular}

Detection limits for traditional spectrophotometer, PA and PTPS have been found in the low part per billion range. Thus PAS and PTPS are competitive with the conventional transmittance spectrophotometry as analytical tools in water. But near field thermal lensing and PDS appear superior in determination of environmental pollutants, where, according to EPA (Environmental Protection Agency /USA) and CEC (Commission of the Europeans Communities) standards, detection limits of $0.1 \mu \mathrm{g} / \mathrm{kg}(0.1 \mathrm{ppb})$ for pesticides in drinking water are required. Figure 4 shows, representatively for all methods used, the experimental TL calibration curve for DNOC ( $/ \mathrm{N}=3$ ). It is interesting to note that independent of a distance between the sample and the pinhole (far field $400 \mathrm{~mm}$, near field $4 \mathrm{~mm}$ ) identical detection limits for both arrangements have been reached. For other pesticides results were also comparable. Further experiments with pulsed excitation (Nd:YAG laser and excimer laser) have been performed. The results will be published elsewhere. Briefly: The $\mathrm{cw}$ argon-ion laser excitation has been shown superior ( factor 2 ) to a pulsed excitation.

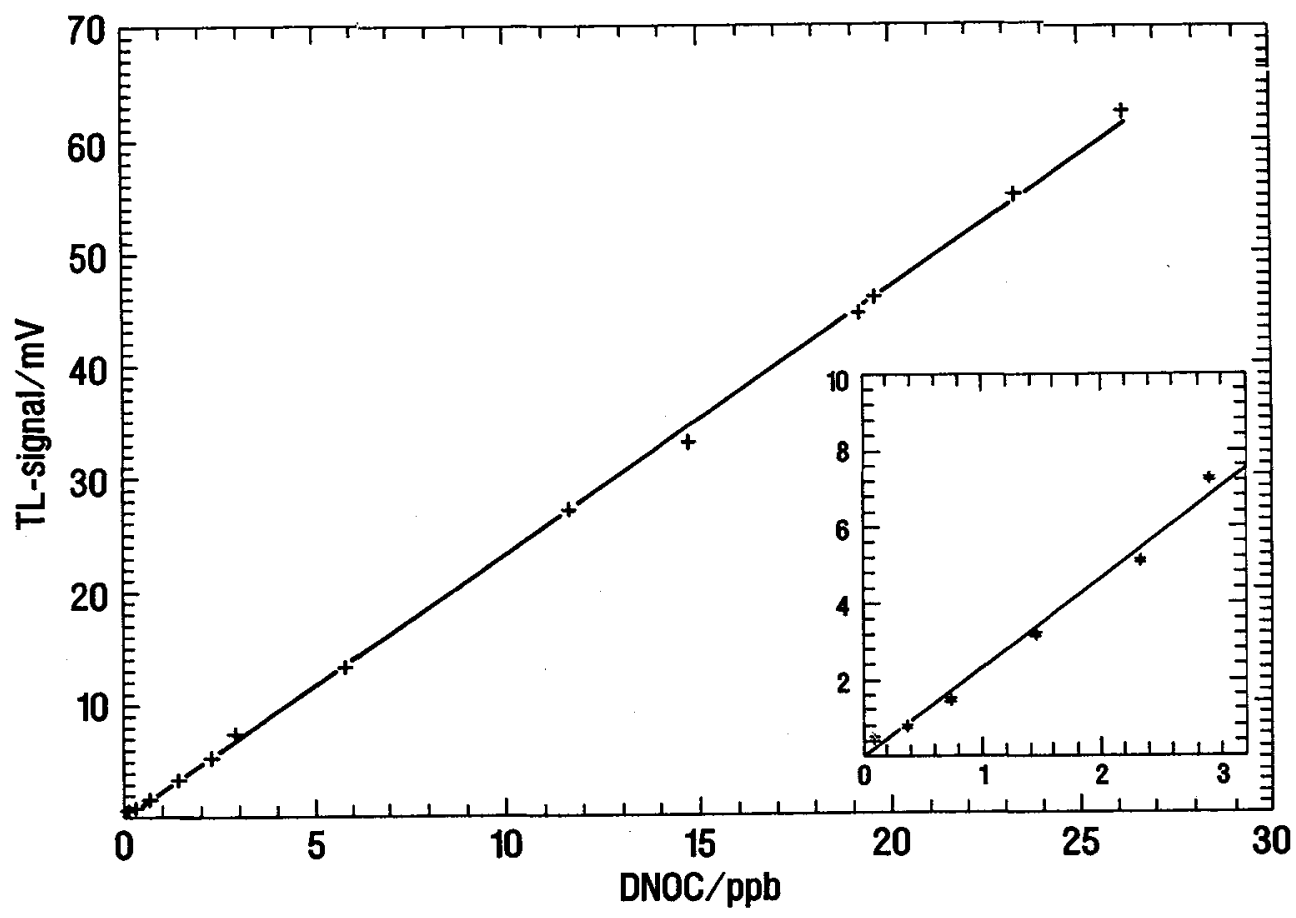

Fig.4: Calibration curve for DNOC obtained with a near field TL 
3.2. High performance liquid chromatography / thermal lensing

A typical HPLC/TL chromatogram with 2,4 dinitrophenol (DNP) and 2-methyl-4,6-dinitrophenol (DNOC) illustrates the performance of our near field thermal lensing detector, with a distance of $4 \mathrm{~mm}$ between the end of the sample cell and pinhole in front of the photodiode, for various concentrations (Fig. 5). The retention times for DNP and DNOC are 6.2 and $7.1 \mathrm{~min}$ with a dead time between injection of the sample and the first thermal signal of $3.3 \mathrm{~min}$. According to Beer's law the peaks decrease proportional to decreasing concentration of the analytes. Detection limits for various schemes (HPLC/TL, HPLC/PAS and HPLC/UV-diode array) are shown in Table 2. In contrast to other authors [4], where "similar results were obtained with the use of laser-induced photoacoustic spectroscopy LIPAS", our own results performed under identical conditions show clearly, that in combination with HPLC the detection limit of thermal lensing is also one order of magnitude better than the laser induced photoacoustic and the UV-diode array system.

Table 2: Comparison of detection limits for DNP/DNOC using different HPLC techniques

\begin{tabular}{|c||c|c|c|}
\hline specimen & UV-diode array & PAS & TL \\
\hline \hline $\mathrm{DNP} / \mu \mathrm{g} / \mathrm{kg}$ & 11 & 7 & 0.7 \\
\hline $\mathrm{DNOC} / \mu \mathrm{g} / \mathrm{kg}$ & 10 & 7 & 0.7 \\
\hline
\end{tabular}

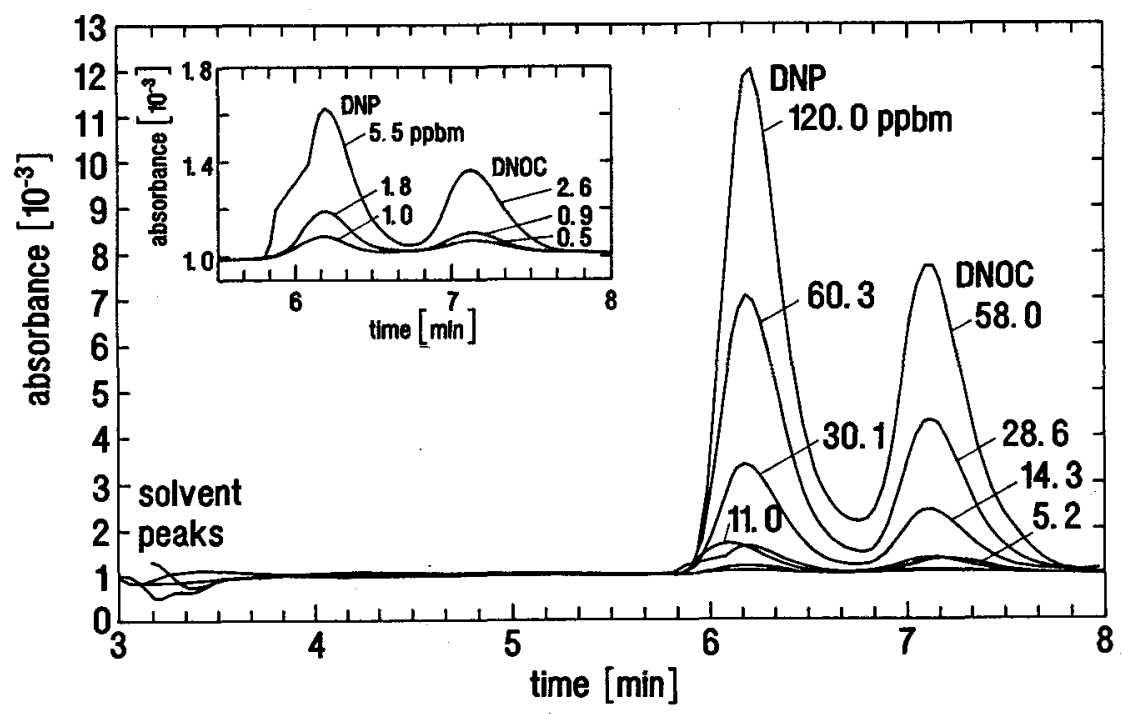

Fig.5: The plot of HPLC/TL chromatograms at various concentrations of pesticides in water.

\section{References}

[1] Poston P.E. and Harris J.M., J.Am.Chem. Soc 112 (1990) 644-650

[2] Adelhelm K., Faubel W. and Ache H.J., Photoacoustic and Photothermal Phenomena III, D. Bicanic (ed.), Optical Sciences 69 (1992) 41-45

[3] Bohnert B., Faubel W. and Ache H.J., Fres.J.Anal.Chem. 343 (1992) 513-517

[4] Rosenzweig Z. and Yeung E.S., Appl. Spectr. 47 (1993) 1175-1179 